\title{
AS TECNOLOGIAS DE INFORMAÇÃO E COMUNICAÇÃO NO CONTEXTO DE PARALISIA CEREBRAL: A SUA PERTINÊNCIA PARA O DESENVOLVIMENTO DA COMUNICAÇÃO E DA APRENDIZAGEM
}

\author{
Sílvia Oliveira ${ }^{1}$ \\ Célia Ribeiro ${ }^{2}$ \\ Catarina Martins $^{3}$
}

\begin{abstract}
Resumo: As Tecnologias de Informação e Comunicação (TIC) têm sido utilizadas no processo de ensino e aprendizagem de crianças/alunos com Necessidades Educativas Especiais nomeadamente com Paralisia Cerebral (PC), com o intuito de potenciar a comunicação e a aprendizagem. O presente trabalho teve como objetivo verificar de que forma as TIC podem ser um contributo para o desenvolvimento da comunicação e aprendizagem em alunos com PC.

Com uma metodologia mista (quantitativa e qualitativa), em que aplicámos um questionário a quarenta e seis professores e observámos dois alunos com PC em intervenções com recurso às TIC, foi possivel concluir, em geral, que a maioria dos professores inquiridos recorre às TIC com frequência na sua prática pedagógica, concordam com o facto de estas contribuírem para a aquisição de aprendizagens, potenciarem o desenvolvimento da comunicação $e$ facilitarem o processo de inclusão dos alunos com PC.

Os dois alunos observados manifestaram-se mais motivados quando realizavam as atividades no computador, demonstrando maior autonomia no desempenho das tarefas. O computador assumiu também um papel relevante no desenvolvimento das capacidades psicomotoras.
\end{abstract}

Palavras-chave: Educação Inclusiva; Paralisia Cerebral; Tecnologias de Informação e Comunicação; Comunicação; Aprendizagem.

\footnotetext{
${ }^{1}$ Mestre em Ciências da Educação, Especialização em Educação Especial. Email: oliveirasilvia1977@gmail.com

${ }^{2}$ Doutorada em Psicologia. Professora Auxiliar na Universidade Católica Portuguesa. Email: cribeiro@crb.ucp.pt

3 Mestre em Psicologia; Doutoranda em Psicologia Experimental. Psicóloga na Associação de Paralisia Cerebral de Viseu. Email: catarinamartins@ @pce.uc.pt
} 


\title{
Title: THE INFORMATION AND COMMUNICATION TECHNOLOGIES IN THE CONTEXT OF CEREBRAL PALSY: ITS IMPORTANCE TO COMMUNICATION AND LEARNING
}

\begin{abstract}
Information and Communication Technologies have been used with students with cerebral palsy in order to develop their communication and learning processes. In this sense, this study was conducted in order to verify how Information and Communication Technologies can be a contribution to the promotion of communication and learning of students with cerebral palsy. With a mixed methodology (quantitative and qualitative), forty-six teachers were submitted to a questionnaire and two students with cerebral palsy were observed using Information and Communication Technologies. It was concluded, in general, that the majority of surveyed teachers use Information and Communication Technologies very often in their daily activity; they agree that technologies contribute to learning as well as that they potentiate the development of communication and facilitate the inclusion of students with Cerebral Palsy. The two observed students seemed to be more motivated when performing activities on the computer, showing greater autonomy in the tasks. Communication technologies also assumed an important role in the development of psychomotor skills.
\end{abstract}

Keywords: Inclusive Education; Cerebral Palsy; Information Technology and Communication; Communication; Learning.

\section{INTRODUÇÃO}

O desenvolvimento dos países, da humanidade e das pessoas realizase através do fator principal que é a Educação (Baptista, 2011). Ao longo dos últimos anos tem-se debatido muito o tema da Educação em geral e da escola, como espaço inclusivo, em particular. A ideia de inclusão remete-nos para as dimensões físicas e atitudinais que permeiam a área escolar, pela inter-relação de diversos elementos como a arquitetura, engenharia, transporte, acesso, experiências, formação e qualificação profissional, métodos pedagógicos, currículo, conhecimentos, sentimentos, comportamentos, valores que coexistem formando este locus extremamente complexo (Mahl, 2012). A escola inclusiva pretende atender a todas as características de todos os alunos, vendo cada um como um todo, não se baseando apenas no seu desempenho académico. A escola inclusiva tenta respeitar três níveis de desenvolvimento essenciais: académico, socio emocional e pessoal, no sentido de maximizar o potencial de cada aluno. Neste contexto, o professor assume um papel fundamental, promovendo a aquisição de conhecimentos e competências 
e o desenvolvimento holístico de todos os alunos, independentemente das suas características individuais.

Entre os instrumentos recentes que se tornaram disponíveis para a atuação dos professores estão as TIC, quer na forma de dispositivos e equipamentos, adaptados ou não, quer sob a forma de programas especiais para computadores. $\mathrm{O}$ termo TIC refere-se à conjugação da tecnologia computacional ou informática com a tecnologia das telecomunicações tendo na Internet a sua mais forte expressão. Estas tecnologias podem ser aplicadas com fins educativos, nomeadamente para apoiar e desenvolver a aprendizagem dos alunos e desenvolver ambientes de aprendizagem.

Atendendo à elevada motivação que mostram os jovens em contacto com estes recursos e a facilidade com que os utilizam, parece pertinente que na prática educativa se investigue como adaptar os conteúdos e as atividades às novas ferramentas, criando novos materiais e cenários inovadores para o ensino-aprendizagem e comunicação (Silva, 2003).

Neste sentido, as TIC podem ser vistas como um grande salto na qualidade de vida de todos os alunos e, especificamente, pelas características que apresentam, dos alunos com PC, pois, através de diversas adaptações possíveis, podem tornar-se num agente facilitador da aprendizagem, instrumento imprescindível na possibilidade de comunicação, assumindo, assim, o papel de fundamental promotor da inclusão escolar e social destes alunos (Souza, 2009). O mesmo autor, partindo de experiências realizadas com crianças com PC, refere que o computador pode ser lúdico, instigante e atrativo, porque possibilita uma resposta imediata, produzindo resultados que, por si só, podem ser interessantes e desafiadores quer para o professor, quer para a criança.

Partindo do pressuposto de Souza (2009), que as potencialidades cognitivas da criança com PC assentam em mecanismos mentais, passíveis de estimulação e de treino e da sua educabilidade em função das características das tarefas, defende-se a necessidade de uma estruturação técnico-pedagógica, de conjuntos coerentes de atividades suscetíveis de potenciar o desenvolvimento destas crianças. As TIC podem constituir-se poderosos auxiliares na estimulação do raciocínio e no desenvolvimento da iniciativa e da autonomia dos alunos com PC.

Importa também reforçar a ideia de que cada aluno apresenta as suas especificidades, os seus interesses, as suas expectativas, as suas capacidades de desenvolvimento. Como tal, o professor necessita de soluções, recursos e estratégias diversificados e adequados, que lhe permitam ajudar os alunos a desenvolver as suas potencialidades, anulando-se, desta feita, as práticas pedagógicas que não respeitam as 
diferenças. Assim, emerge esta investigação, que objetiva verificar de que forma as TIC podem ser um contributo para a promoção da comunicação e da aprendizagem dos alunos com PC.

\section{CONCEITO DE PARALISIA CEREBRAL}

A PC trata-se de uma alteração persistente do movimento e da postura que é causada por um processo patológico no cérebro imaturo, que leva à disfunção motora, cuja principal causa é a lesão encefálica precoce, não evolutiva, de origem fetal ou infantil. As disfunções motoras da PC podem ser acompanhadas por alterações de sensação, cognição, comunicação e conduta, por epilepsia e por problemas músculoesqueléticos secundários (Rosenbaum, Paneth, Levinton, Goldstein, \& Bax, 2007), havendo, recentemente maior ênfase aos problemas percetivos (Martins, 2013; Martins \& Oliveira, 2013).

Há um enorme espectro de gravidade desta condição (Fonseca \& Lima, 2009). Algumas crianças têm perturbações ligeiras, quase impercetíveis, outras possuem uma grave incapacidade, sendo totalmente dependentes nas atividades da vida diária. Para além das perturbações motoras, são frequentes o atraso cognitivo, as perturbações visuais e auditivas, a epilepsia, as dificuldades de aprendizagem e o défice de atenção.

Leite e Prado (2004) referem que a PC inclui numerosas afeções com várias etiologias e quadros clínicos diversos, tendo em comum o facto de afetarem o Sistema Nervoso Central das crianças, com um carácter crónico. Apontam, assim, quatro tipos: espástico, atáxico, extrapiramidal ou disquinético e misto.

Ainda que o conceito de PC não inclua lesões evolutivas, como as produzidas por doenças degenerativas ou tumor cerebral, deve ter-se em conta que as consequências da lesão variam ao longo do desenvolvimento da criança e que, por isso, não existem dois casos iguais na PC. Enquanto algumas crianças têm perturbações ligeiras, que as tornam desajeitadas a andar, falar ou usar as mãos, outras são gravemente afetadas com incapacidade motora, tornando-as totalmente dependentes de terceiros.

Apesar de a PC resultar de uma lesão cerebral irreversível, podem alcançar-se progressos muito importantes que farão com que a pessoa com PC se aproxime de um funcionamento mais adaptativo se a reabilitação física e a educação forem adequadas (Martins \& Leitão, 2012). 


\section{AS TECNOLOGIAS DE INFORMAÇÃO E COMUNICAÇÃO EM CONTEXTOS EDUCATIVOS}

O computador faz parte do quotidiano de milhares de pessoas e o uso das TIC é usual na nossa sociedade. Uma definição adotada pela União Europeia (2001) assinala que as TIC são um termo que se aplica atualmente para fazer referência a uma ampla diversidade de serviços, aplicações e tecnologias, que empregam diversos tipos de equipamentos e de programas informáticos, e que às vezes são transmitidas por meio das redes de telecomunicações. As TIC incluem serviços conhecidos de telecomunicações semelhantes aos serviços de telefone fixo, telefone móvel e fax, que se utilizam combinados com suporte físico e lógico para constituir a base de uma diversidade de outros serviços, como o correio eletrónico, a transferência de arquivos de um computador para outro, e, em particular, a Internet, que potencialmente permite que estejam ligados todos os computadores, oferecendo acesso a fontes de conhecimento e informação armazenados em computadores de todo o mundo. A relevância das TIC não é a tecnologia em si, mas o facto de permitir o acesso às comunicações, à informação e ao conhecimento, elementos cada vez mais importantes na interação económica e social dos tempos atuais (Comunicação da Comissão ao Conselho e ao Parlamento Europeu, 2002).

O conceito TIC diz respeito a um conjunto de ferramentas, sistemas e aplicações microeletrónicas, informáticas e de telecomunicação que dão acesso à aquisição, produção, armazenamento, processamento, transmissão e partilha de dados em formato texto, som, imagem e/ou multimédia sustentada por uma rede de conectividade globalizada (Martínez, 2004). As TIC possibilitam, assim, ao Homem, como se depreende das definições supracitadas, classificar, armazenar, selecionar e transformar dados em informação.

Na última década, assistimos a um aumento significativo na utilização das tecnologias na "sociedade da informação" em todos os domínios e atividades. A escola, enquanto instituição social, também não pode ficar indiferente às TIC. Neste sentido, é cada vez mais evidente a necessidade de os docentes se adaptarem às novas tecnologias e promoverem a sua utilização dentro do contexto educativo da sala de aula. Estas possibilitam a alteração de modelos de reprodução de informação para um modelo baseado na construção partilhada do conhecimento "(...) aberto aos contextos sociais e culturais, à diversidade dos alunos, aos seus conhecimentos, experimentações e interesses, ou seja, em constituir-se como uma verdadeira Comunidade de Aprendizagem" (Ponte, 2002, p. 77). 
De acordo com o mesmo autor, é mais importante a capacidade de lidar com a complexidade de resolver problemas de localizar e usar a informação pertinente, de criticar e avaliar os resultados conseguidos do que o saber factual. Por isso, para muitos autores, como Pastor (1994), Rodrigues (1988) e Montoya (2000), o recurso às TIC ajuda na realização das atividades básicas como comunicar, aprender, trabalhar ou brincar, pois o acesso à informação através das TIC é mais enriquecido, apelativo, motivante e multissensorial (Flores, Peres, \& Escola, 2009).

Damásio $(2007$, p. 331) vai mais além e expressa que "enquanto discurso e tecnologia, as TIC operam transformações sobre a presença social e sobre a presença cognitiva e, enquanto serviços, elas operam transformações sobre a presença cognitiva e sobre a presença de ensino". Esta ideia é corroborada por Ribeiro (2011), que afirma que o envolvimento num ambiente de aprendizagem facilita a exploração e reciprocamente a exploração promove o envolvimento.

Assim, as TIC desenvolvem a autonomia e socialização dos alunos, sobretudo daqueles que têm Necessidades Educativas Especiais (NEE), pois podem ser utilizadas como suportes ou como elementos de substituição de funções que o corpo não consegue ou tem dificuldade em executar. As TIC ajudam assim a rentabilizar as aprendizagens, pois ajudam na organização e planificação das atividades. Muitas vezes, as TIC são, segundo Rodrigues (1988), a única possibilidade para transmitir um pensamento, uma vontade ou uma mensagem intencional.

Também para Correia (2003), as TIC contribuíram para "diminuir as incapacidades e desvantagens destes alunos, aumentando a sua integração escolar e social" (p. 43), ao permitirem melhorar os resultados em certas práticas pedagógicas como o encorajamento, o treino, a aplicação de conhecimento, a comunicação e o espírito de iniciativa. No entanto, nenhuma potencialidade das TIC pode efetivar-se sem uma nova atitude e uma nova cultura de utilização.

\section{AS TECNOLOGIAS DE INFORMAÇÃO E COMUNICAÇÃO NA EDUCAÇÃO ESPECIAL}

O desenvolvimento do indivíduo está ligado à capacidade de comunicar, enquanto forma de intervenção sobre o meio circundante, já que a comunicação está presente em todos os contextos do quotidiano do indivíduo (Cruz, 2009). Para Morato (1998), as TIC proporcionam às crianças com NEE a comunicação com os outros, numa condição autónoma de afirmação da sua individualidade intencional, pela utilização de códigos alternativos e de dispositivos de síntese vocal (Morato,1998). De acordo com Selwyn (2008), o uso das TIC não é um pré-requisito para 
sobreviver na sociedade do século XXI, é quase certamente um elemento integral para prosperar na sociedade deste século, ou seja, as TIC ajudam a ter sucesso na sociedade do século XXI.

Em 2005, Williams descreveu um estudo sobre a utilização das TIC num ambiente de aprendizagem multimédia para pessoas com NEE no artigo intitulado Using information and communication tecnology with special educational needs students. Este estudo qualitativo pretendia explorar os benefícios que se encontram na utilização das TIC e as restrições e as barreiras que enfrentam as pessoas com NEE, o ambiente em geral, a informação e as suas necessidades. Através da entrevista semiestruturada, o autor analisou as necessidades de informação dos professores, as experiências dos sujeitos com as TIC e determinou o seu impacto nas aprendizagens, as vantagens e os benefícios do seu uso, as barreiras que dificultam a sua aplicação e como estas podem ser superadas, e quais os requisitos necessários para desenvolver a aprendizagem multimédia, segundo os professores. Neste estudo, entre outras conclusões, observou-se que a maioria dos entrevistados via o computador e a Internet como ferramentas úteis para o ensino, devido à melhoria das experiências de aprendizagem dos alunos. Salientou-se também a baixa qualidade dos equipamentos.

Em 2006, na Universidade do Minho, Moura (2006) procurou compreender de que modo a escola e os seus agentes educativos respondem às exigências pedagógicas, metodológicas e de formação que implicam a inclusão das TIC no processo de ensino e aprendizagem das crianças e jovens com PC. A pesquisa foi orientada para verificar a existência ou não das condições necessárias para que as TIC sejam eficazes, indo ao encontro dos objetivos com que são utilizadas. Os resultados mostraram que as TIC têm um papel importante no desenvolvimento da autonomia, da aprendizagem e da comunicação desses alunos. Contudo, verificou-se que existem muitos fatores que determinam o fracasso ou o êxito da introdução e da utilização das TIC nos contextos educativos em questão. Sendo um deles a falta de formação por parte dos professores que apoiam estes alunos e o outro a falta de condições físicas.

Recentemente, foi publicado um relatório do Instituto para as Tecnologias da Informação da UNESCO (2011), que tem como objetivo apresentar exemplos de casos de utilização das TIC em diferentes contextos educacionais para demonstrar o seu potencial, enquanto instrumentos de apoio à aprendizagem e também de inclusão de alunos com NEE e pessoas com deficiência e incapacidade. Este relatório da UNESCO apresenta doze Estudos de Casos e mais de vinte exemplos 
oriundos de dezoito países diferentes e pretendia destacar as diferentes possibilidades e os potenciais benefícios no uso das TIC em diferentes contextos escolares com alunos com NEE. Para isso, fez-se a recolha de vários exemplos em diferentes países e contextos educacionais. Concluise que há três aspetos que continuam cruciais para o desenvolvimento nacional das estratégias da inclusão informática e a sua implementação com sucesso. Sendo estes: o aumento da desvantagem e acesso dos grupos excluídos à infraestrutura de TIC; a promoção da literacia básica em TIC e os programas de formação profissional dirigidos especificamente aos segmentos mais vulneráveis da sociedade; o apoio regional, sub-regional e interpaíses, cooperação e intercâmbio de boas práticas sobre a extensão da utilização das TIC para grupos excluídos.

Os exemplos apresentados neste relatório mostraram, claramente, o impacto das TIC na educação das pessoas com NEE, podendo ser consideradas uma ferramenta valiosa na sua educação e assim aumentar o seu acesso a infraestruturas e sucesso. Contudo, essa meta não é um fim. As TIC ajudam na inclusão educacional e social dos alunos com NEE, porquanto podem aumentar a sua qualidade de vida. De acordo com o mesmo relatório, aumentar o acesso às TIC pode ser benéfico para todos os cidadãos e não apenas para aqueles que têm NEE, havendo, por isso, necessidade de promover a literacia básica das TIC.

\section{METODOLOGIA}

\subsection{Problemática}

A problemática das NEE continua a ser uma questão bastante complexa e pertinente na escola atual, pois continuam a acentuar-se mais os limites do que as potencialidades das crianças e jovens com NEE. As limitações apresentadas condicionam a pessoa nos seus desempenhos relacionais e afetam-nas na sua afirmação como membro de pleno direito da comunidade a que pertence.

Segundo Souza (2009), é a disfunção motora das crianças com PC que faz com que elas não produzam respostas consistentes que ajudam a estruturar o seu pensamento, pois falta-lhes experiências com o seu meio envolvente. Os alunos com PC estão limitados na sua interação com o ambiente e na respetiva promoção do seu processo de desenvolvimento, devido à incapacidade motora, à incapacidade de produzir fala articulada compreensível e à presença de défices sensoriais e percetíveis. A normal progressão é afetada pelo facto de determinadas fases do desenvolvimento surgirem mais tarde ou nunca (Fonseca \& Lima, 2009).

Normalmente, a lesão cerebral afeta, como já referido, o desenvolvimento psicomotor da criança e a área da linguagem. A criança 
vê-se comprometida pela persistência de reflexos primitivos que é incapaz de inibir (Fonseca \& Lima, 2009). Assim, a criança com PC mostra uma certa rigidez nas formas de expressão como a mímica e o gesto, a coordenação de movimentos finos e a expressão oral. Os órgãos da fala são quase sempre afetados pela lesão cerebral, causada pela perturbação mais ou menos grave no controlo dos órgãos motores fonadores, que podem afetar o ato de falar ou até impedi-lo por completo. Esta dificuldade também se pode manifestar a nível da mastigação, deglutinação, controlo da saliva ou respiração (Souza, 2009).

Apesar destes problemas a nível da linguagem expressiva, a compreensão da linguagem por vezes não é afetada. $O$ seu desenvolvimento é afetado quando existem problemas cognitivos ou de audição. Nestes casos, torna-se mais difícil o processo de aquisição da linguagem como também do desenvolvimento da linguagem compreensiva (Souza, 2009).

Desde cedo, a criança com PC tem dificuldades na interação com os outros, pois não consegue produzir os gestos e os sons que o meio social dá valor e reconhece como funções comunicativas. Segundo Basil (1995), estas crianças encontram dificuldades em produzir mudanças no comportamento das outras pessoas, no sentindo de as fazer interagir com elas e este défice comunicativo limita-as não só no seu desenvolvimento cognitivo e social, como também na construção da sua personalidade.

Além disso, o facto das crianças com PC estarem impedidas de manipular e de agir fisicamente sobre o mundo que as rodeia, explorandoo livremente, vai interferir também no desenvolvimento da inteligência sensoriomotora e como consequência pode influenciar de modo negativo o desenvolvimento do pensamento pré-operatório, operatório e formal. É a quantidade e a qualidade das interações com o meio que determinam o desenvolvimento social e emocional da criança (Fonseca \& Lima, 2009).

Basil (1995) é de opinião que a motivação e o investimento necessários a qualquer atividade da criança diminuem, quando esta experimenta o fracasso quando age. Ela sente-se incapaz e isso pode levála a desistir, pois, por vezes, é o próprio ambiente que não lhe dá o feedback pretendido.

As TIC dão aos alunos, então, a possibilidade de ganhar maior autonomia ao longo das suas aprendizagens através da exploração ativa do mundo que as rodeia, levando-os assim a aprender a investigar, questionar e construir o seu próprio conhecimento.

De uma forma geral, as desordens que afetam os alunos com PC dificultam ou impedem a sua utilização de meios convencionais de escrita e de comunicação. Neste sentido, as TIC podem contribuir para 
ultrapassar ou reduzir dificuldades manifestadas pelos alunos com PC e ajudá-los na sua inclusão escolar e social, dado que se tem verificado, ao longo dos anos, que as TIC contribuíram para alterações comportamentais e aquisições de aprendizagens por parte dos alunos que as utilizaram.

Decorrente do exposto, formulou-se a seguinte questão de partida, fio condutor desta investigação: De que forma as TIC podem ser um contributo para a promoção da comunicação e aprendizagem dos alunos com PC?

\subsection{Objetivos}

A contextualização e definição dos objetivos de trabalho são, na opinião de Bell (2008), fundamentais na elaboração de investigações. Assim, estruturaram-se como objetivos para este estudo:

1) Conhecer as estratégias utilizadas com alunos com PC;

2) Conhecer as atividades a que os alunos com PC respondem e aderem melhor;

3) Identificar a frequência de utilização das TIC nas práticas pedagógicas com alunos com PC;

4) Identificar a frequência de utilização do computador em sala de aula;

5) Conhecer a importância da utilização das TIC nas práticas pedagógicas com alunos com PC;

6) Observar a utilização das TIC em dois alunos com PC quanto ao seu contributo para a promoção da comunicação e aprendizagem.

\subsection{Tipo de investigação}

Adotou-se um tipo de investigação considerado misto, pois recorreuse à uma abordagem qualitativa e quantitativa, visto abranger a descrição de dois casos de estudo e a aplicação e análise de um questionário.

Segundo Almeida e Freire (2003), enquanto a abordagem quantitativa caracteriza-se pela utilização de quantificações nas modalidades de recolha de informações através de técnicas estatísticas, a abordagem qualitativa abrange estudos nos quais o observador se localiza no campo de observação, constituindo-se, portanto, num enfoque naturalístico e interpretativo da realidade (Bell, 2003).

\subsection{Caracterização dos participantes}

\section{Alunos Observados}

$\mathbf{O}$ aluno $\mathbf{X}$ tem 8 anos e é o terceiro filho de um casal jovem. Está incluído numa turma com 10 alunos do $2^{\circ}$ ano de escolaridade. Apesar de não apresentar multideficiência frequenta a Unidade de Apoio 
Especializado para a Educação de Alunos com Multideficiência e Surdocegueira Congénita (UAEM) durante algumas horas do dia, para poder beneficiar de atividades mais específicas e das terapias aí disponíveis, nomeadamente, a terapia da fala. É bem aceite pelos colegas e pela professora titular de turma. Tem acompanhamento de uma tarefeira dentro e fora da sala de aula, excetuando os períodos em que está acompanhado pela professora de Educação Especial e pela Terapeuta da Fala.

De acordo com o seu Programa Educativo Individual (PEI) do ano letivo 2010/2011, o aluno $X$ "usa talas, devido ao elevado comprometimento manual, e tendência a manter padrões desadequados. Precisa de ajuda e orientação muito específicas nas atividades relacionadas com a motricidade fina (d440 atividades de motricidade fina da mão)". Por isso, segundo o mesmo documento, "o trabalho futuro com o aluno deve passar basicamente pelo uso de computador e software específico (e130 produtos e tecnologias para a educação). Precisa também de ser muito estimulado ao nível da imitação (d130imitar), da aquisição de conceitos (d137adquirir conceitos), da atenção (d161 concentrar e atenção). Apresenta dificuldades específicas em terminar as tarefas (d210 levar a cabo uma tarefa única), devendo ser muito motivado neste sentido". Como não possui comunicação verbal, usa tabelas de comunicação com símbolos pictográficos para a comunicação.

De acordo com as informações médicas que constam do seu processo individual, a Ressonância Magnética Crânio Encefálica revelou "Extensa malformação cortical do tipo micropoligiria difusa". Segundo as mesmas informações, ele "nasceu às 41 semanas, de parto eutócico, com antropometria adequada e boa vitalidade". Nos primeiros meses de vida foi transferido para o Hospital Pediátrico de Coimbra visto revelar "tetraparésia com tónus variável", "falta de competências motoras", "infeções respiratórias frequentes" e "evolução ponderal irregular" (provocada por problemas de deglutinação). De acordo com as informações médicas, "apresenta um quadro de PC e a mãe referiu que o aluno $\mathrm{X}$ tem a caixa torácica fechada, o que é um grande problema, pois esta vai abrindo aos poucos mas não o suficiente". De acordo com o relatório da consulta de desenvolvimento, o aluno apresenta limitações que vão condicionar todo o seu desenvolvimento, nomeadamente, limitações ao nível das funções cognitivas básicas e a nível global; limitações na linguagem expressiva e na autonomia; nas funções neuromusculo-esqueléticas e funções relacionadas com o movimento. Manifesta também limitações moderadas a nível de atenção, memória, orientação temporo-espacial e perceção. 
A aluna Y tem 6 anos, é a primeira filha de pais jovens e saudáveis. Atualmente vive com a mãe em casa dos avós maternos. Iniciou em 2009 o pré-escolar num Jardim de Infância perto da sua residência, tendo sido transferida para o atual Jardim de Infância com UAEM no início deste ano letivo. Está inserida numa turma do Jardim de Infância com 22 alunos, mas frequenta a tempo parcial a Unidade para poder beneficiar de atividades mais específicas e das terapias aí disponíveis, como a terapia da fala (PEI, 2011/2012). Segundo as informações que constam do seu processo individual, a gravidez foi normal, durou 40 semanas, "nasceu por ventosa, após preparação para cesariana". A aluna Y apresenta "um quadro neurológico compatível com microcefalia atáxica por epilepsia (PC) e atraso do desenvolvimento psicomotor. Apresenta também, de acordo com o relatório médico de 26/06/2009, "Microcefalia Retrognatia" e "Estrabismo divergente".

\section{Professores}

Foram inquiridos 46 professores, $91,3 \%(\mathrm{n}=42)$ são do sexo feminino e $8,7 \%(n=4)$ são do sexo masculino; $41,3 \%(n=19)$ tem idade igual ou inferior a 34 anos; $39,1 \%(n=18)$ tem entre 35 e 44 anos e $19,6 \%(n=9)$ tem idade igual ou superior a 45 anos. Observa-se que o grupo mais representativo tem idade igual ou inferior a 34 anos. A idade mínima observada foi de 33 anos e a máxima de 55.

Relativamente ao tempo de serviço, verifica-se que $41,3 \%$ ( $n=9)$ dos inquiridos tem tempo igual ou inferior a cinco anos de serviço; 32,6\% $(n=15)$ tem entre seis a quinze e $26,1 \%(n=12)$ tem dezasseis ou mais anos de serviço. Refira-se que o grupo mais representativo dos inquiridos tem cinco ou menos anos de tempo de serviço.

No que concerne ao grupo profissional, a maioria está inserida no grupo $110(\mathrm{n}=17 ; 37 \%) ; 17,4 \%(\mathrm{n}=8)$ no grupo $240 ; 13 \%(\mathrm{n}=6)$ no grupo 100; 8,7\% está no grupo 910 e, a mesma percentagem está no 330/300; $2,2 \%(\mathrm{n}=1)$ no grupo $910 / 110$ e, com igual valor percentual, está no grupo 420; 410; 240/110; 450; 250/610 e 320.

Verifica-se que $21,8 \% \quad(n=10)$ dos inquiridos encontra-se numa situação profissional de Nomeação Definitiva Quadro de Escola/Quadro de Agrupamento; $15,2 \% \quad(n=7)$ apresenta uma situação Nomeação Definitiva Quadro de Zona Pedagógica e 63\% $(\mathrm{n}=29)$ dos professores encontram-se contratados, correspondendo este último ao grupo mais representativo.

Quanto ao nível de ensino que os inquiridos lecionam, constatou-se que $4,5 \%(\mathrm{n}=2)$ leciona no pré-escolar e no $1^{\circ}$ ciclo e, a mesma percentagem, no $910 ; 11,4 \%(n=5)$ leciona apenas no pré-escolar; $2,3 \%$ $(\mathrm{n}=1)$ leciona a todos os níveis e, na mesma percentagem leciona na educação especial e nos $1^{\circ}$ e $2^{\circ}$ ciclos; $34,1 \%(n=15)$ dos inquiridos 
lecionam no $1^{\circ}$ ciclo; $13,6 \%(\mathrm{n}=6)$ lecionam no $3^{\circ}$ ciclo/ secundário; $18,2 \%(n=8)$ lecionam no $2^{\circ}$ ciclo e $6,8 \%(n=3)$ dos inquiridos lecionam nos $2^{\circ}$ e $3^{\circ}$ ciclos. O grupo mais representativo é o dos professores que lecionam no $1^{\circ}$ ciclo.

\subsection{Instrumentos de investigação}

Utilizámos o questionário em formato de papel e via online, como um dos instrumentos de recolha de dados. É constituído por duas partes:

Parte I - Caracterização dos inquiridos: contém 10 questões que permitem recolher informações sobre: idade, sexo, tempo de serviço, grupo profissional, situação profissional, nível de ensino que leciona, ter ou ter tido alunos com PC na sala de aula, o número de alunos, grau de informação que possui sobre a PC, onde obteve informação/formação sobre a PC, estar ou não preparado suficientemente para trabalhar com alunos com PC.

Parte II - A utilização das TIC no processo de ensino e aprendizagem: constituída por 9 questões, onde constam 3 escalas de tipo Likert, que permitem obter as seguintes informações: dificuldades que os alunos com PC apresentam no seu processo de ensino e aprendizagem; estratégias utilizadas em alunos com PC para os ajudar a colmatar as suas dificuldades; atividades a que os alunos com PC respondem melhor; ordenação das atividades a que os alunos com PC aderem melhor; utilização das TIC nas práticas pedagógicas com alunos com PC; utilização do computador nas aulas; finalidade da utilização do computador; uso das TIC em contexto educativo; importância da utilização das TIC na prática com alunos com PC.

As escalas de tipo Likert contêm as seguintes opções de resposta:

Questão 14) 5= mais importante e 1= menos importante.

Questão 17) Nunca, Raramente, Frequentemente, Muitas vezes

Questões 18) e 19) $\begin{aligned} & \text { Discordo totalmente, } \\ & \text { Concordo totalmente }\end{aligned}$

Para além dos questionários, foram construídas grelhas para a observação de dois alunos em contexto de utilização das TIC.

\subsection{Procedimentos}

Tanto as grelhas de observação, como o questionário, foram elaborados a partir de grelhas e questionários já existentes, designadamente dos autores Silva (2004), Moura (2006) e Fradinho 
(2009), tendo os mesmos sido posteriormente adaptados à nossa investigação com a devida permissão dos autores

Após solicitada a autorização aos Diretores de Agrupamentos de Escolas da Cidade de Viseu para a aplicação dos questionários e realização das observações, procedeu-se à aplicação dos questionários nos meses de março a junho de 2012. Foram distribuídos 100 questionários e recebidos 46. Os questionários foram preenchidos de forma individual e anónima para que os inquiridos pudessem, sem quaisquer restrições, expressar as suas opiniões.

As observações dos alunos foram efetuadas durante os meses de maio e junho de 2012, em contexto de escola, no total de 7 sessões com o aluno $\mathrm{X}$ e 3 com a aluna $\mathrm{Y}$, com 30 a 45 minutos cada.

\section{RESULTADOS}

\subsection{Apresentação dos resultados}

Quanto às estratégias utilizadas em alunos com PC para os ajudar a colmatar as dificuldades, em conformidade com os professores inquiridos que já trabalharam com alunos com PC, a maioria (64,3\%) mencionou recorrer a tecnologias de apoio, $21,4 \%$ optou pela tutoria, ensino individualizado e pelo trabalho de pares, $14,3 \%$ referiu recorrer à sensibilização da comunidade escolar, à formação e ao "trabalho educativo" (cf. Tabela 1).

\section{Tabela 1}

Estratégias utilizadas em alunos com Paralisia Cerebral para os ajudar a colmatar as dificuldades

\begin{tabular}{lccc}
\hline \multicolumn{1}{c}{ Estratégias } & $\mathrm{n}$ & $\%$ & \% válida \\
\hline Recurso a tecnologias de apoio & 9 & 19,6 & 64,3 \\
$\begin{array}{l}\text { Sensibilização da comunidade escolar; } \\
\text { formação; trabalho educativo }\end{array}$ & 2 & 4,3 & 14,3 \\
$\begin{array}{l}\text { Tutoria; ensino individualizado; trabalho } \\
\text { de pares }\end{array}$ & 3 & 6,5 & 21,4 \\
$\begin{array}{l}\text { Não Respondeu } \\
\text { Total }\end{array}$ & 32 & 69,6 & 100,0 \\
\hline
\end{tabular}

No que concerne às atividades a que os alunos com $\mathrm{PC}$ respondem melhor, 77,3\% dos professores inquiridos mencionam que é de forma individual e 22,7\% referem que é em grupo (cf. Tabela 2). 
Tabela 2

Atividades a que os alunos com Paralisia Cerebral respondem melhor

\begin{tabular}{lccc}
\hline Atividades & $\mathrm{n}$ & $\%$ & $\%$ Válida \\
\hline Em grupo & 5 & 10,9 & 22,7 \\
Individuais & 17 & 37,0 & 77,3 \\
Não Respondeu & 24 & 52,2 & 100,0 \\
Total & 46 & 100,0 & \\
\hline
\end{tabular}

No que concerne às atividades a que os alunos com $\mathrm{PC}$ aderem melhor, constatámos que $30,4 \%$ dos sujeitos inquiridos indicaram as atividades de papel e lápis como aquelas a que os alunos com PC aderem melhor, $26,1 \%$ referiram atividades multimédia, $23,9 \%$ indicaram as atividades de expressão plástica, $21,7 \%$ mencionaram as atividades físicas e 19,6\% indicaram as atividades musicais (cf. Tabela 3).

Tabela 3

Atividades a que os alunos com Paralisia Cerebral aderem melhor

\begin{tabular}{lcc}
\hline \multicolumn{1}{c}{ Ordem das atividades } & $\mathrm{n}$ & $\%$ \\
\hline Atividade de papel e lápis & 14 & 30,4 \\
Atividades físicas & 10 & 21,7 \\
Atividades de expressão plástica & 11 & 23,9 \\
Atividades musicais & 9 & 19,6 \\
Atividades multimédia & 12 & 26,1 \\
Total & 46 & 100,0 \\
\hline
\end{tabular}

Quanto à utilização das TIC nas práticas pedagógicas com alunos com PC constatou-se que a maioria dos professores inquiridos $(57,9 \%)$ recorre às mesmas com muita frequência, havendo, no entanto, professores que referiram nunca as utilizar $(15,8 \%)$ e/ou que o fazem raramente $(21,1 \%)$ (cf. Tabela 4).

Tabela 4

Utilização das TIC nas práticas pedagógicas com alunos com Paralisia Cerebral

\begin{tabular}{lccc}
\hline Utilização das TIC & $\mathrm{n}$ & $\%$ & $\%$ Válida \\
\hline Nunca & 3 & 6,5 & 15,8 \\
Raramente & 4 & 8,7 & 21,1 \\
Por vezes & 1 & 2,2 & 5,3 \\
Frequentemente & 11 & 23,9 & 57,9 \\
Não Respondeu & 27 & 58,7 & 100,0 \\
Total & 46 & 100,0 & \\
\hline
\end{tabular}

A maioria dos professores $(70,6 \%)$ refere a frequente utilização do computador em contexto de sala de aula (cf. Tabela 5). 
Tabela 5

Utilização do computador nas aulas

\begin{tabular}{lccc}
\hline $\begin{array}{c}\text { Frequência de utilização } \\
\text { do computador }\end{array}$ & $\mathrm{n}$ & $\%$ & $\%$ válida \\
\hline Nunca & 0 & 0,0 & 0,0 \\
Raramente & 2 & 4,3 & 5,9 \\
Por vezes & 8 & 17,4 & 23,5 \\
Frequentemente & 24 & 52,2 & 70,6 \\
Não Respondeu & 12 & 26,1 & 100,0 \\
Total & 46 & 100,0 & \\
\hline
\end{tabular}

No que concerne à importância da utilização das TIC na prática com alunos com PC, observámos que os $39,1 \%$ dos docentes inquiridos concordam com o facto de as mesmas contribuírem para a aquisição de aprendizagens; ajudarem os alunos a ultrapassar/minimizar algumas das dificuldades dos alunos (32,6\%); potenciar o desenvolvimento da comunicação $(32,6 \%)$. Verificámos também que 34,8\% dos docentes consideram que as TIC facilitam o processo de inclusão dos alunos com PC; que as mesmas têm potencialidades para inovar e melhorar o processo educativo destes alunos $(32,6 \%)$; que melhoram a sua qualidade de vida e os mesmos desenvolvem competências escolares $(34,8 \%)$; que os ajudam a adquirir conhecimentos novos e a consolidá-los $(32,6 \%)$ (cf. Tabela 6).

Tabela 6

A importância da utilização das TIC na prática com alunos com Paralisia Cerebral

\begin{tabular}{|c|c|c|c|c|c|}
\hline \multicolumn{2}{|c|}{$\begin{array}{l}\text { Importância da utilização das TIC na prática com } \\
\text { alunos com Paralisia Cerebral }\end{array}$} & \multirow{2}{*}{$\frac{\mathrm{n}}{0}$} & \multirow{2}{*}{$\frac{\%}{0,0}$} & \multirow[t]{2}{*}{$\mathrm{M}$} & DP \\
\hline \multirow{4}{*}{$\begin{array}{l}\text { Tem contribuído para a } \\
\text { aquisição de aprendizagens }\end{array}$} & Discordo Totalmente & & & & \multirow{4}{*}{0,488} \\
\hline & Discordo & 0 & 0,0 & \multirow{3}{*}{3,64} & \\
\hline & Concordo & 10 & 21,7 & & \\
\hline & Concordo Totalmente & 18 & 39,1 & & \\
\hline \multirow{4}{*}{$\begin{array}{l}\text { Ultrapassam/minimizam } \\
\text { algumas das dificuldades } \\
\text { dos alunos }\end{array}$} & Discordo Totalmente & 0 & 0,0 & \multirow{4}{*}{3,52} & \multirow{4}{*}{0,509} \\
\hline & Discordo & 0 & 0,0 & & \\
\hline & Concordo & 14 & 30,4 & & \\
\hline & Concordo Totalmente & 15 & 32,6 & & \\
\hline \multirow{4}{*}{$\begin{array}{l}\text { Facilitam o processo de } \\
\text { inclusão das crianças com } \\
\text { Paralisia Cerebral }\end{array}$} & Discordo Totalmente & 0 & 0,0 & \multirow{4}{*}{3,38} & \multirow{4}{*}{0,561} \\
\hline & Discordo & 1 & 2,2 & & \\
\hline & Concordo & 16 & 34,8 & & \\
\hline & Concordo Totalmente & 12 & 26,1 & & \\
\hline \multirow{4}{*}{$\begin{array}{l}\text { Têm potencialidades para } \\
\text { inovar e melhorar o processo } \\
\text { educativo das crianças com } \\
\text { Paralisia Cerebral }\end{array}$} & Discordo Totalmente & 0 & 0,0 & \multirow{4}{*}{3,48} & \multirow{4}{*}{0,509} \\
\hline & Discordo & 0 & 0,0 & & \\
\hline & Concordo & 15 & 32,6 & & \\
\hline & Concordo Totalmente & 14 & 30,4 & & \\
\hline \multirow{4}{*}{$\begin{array}{l}\text { Melhoram a sua qualidade } \\
\text { de vida }\end{array}$} & Discordo Totalmente & 0 & 0,0 & \multirow{4}{*}{3,45} & \multirow{4}{*}{0,506} \\
\hline & Discordo & 0 & 0,0 & & \\
\hline & Concordo & 16 & 34,8 & & \\
\hline & Concordo Totalmente & 13 & 28,3 & & \\
\hline
\end{tabular}




\begin{tabular}{|c|c|c|c|c|c|}
\hline \multicolumn{2}{|c|}{$\begin{array}{l}\text { Importância da utilização das TIC na prática com } \\
\text { alunos com Paralisia Cerebral }\end{array}$} & \multirow{2}{*}{$\frac{\mathrm{n}}{0}$} & \multirow{2}{*}{$\frac{\%}{0,0}$} & \multirow[t]{2}{*}{ M } & DP \\
\hline \multirow{4}{*}{$\begin{array}{l}\text { Desenvolvem a } \\
\text { comunicação }\end{array}$} & Discordo Totalmente & & & & \multirow{4}{*}{0,509} \\
\hline & Discordo & 0 & 0,0 & \multirow{3}{*}{3,52} & \\
\hline & Concordo & 14 & 30,4 & & \\
\hline & Concordo Totalmente & 15 & 32,6 & & \\
\hline \multirow{4}{*}{$\begin{array}{l}\text { Tem contribuído para a } \\
\text { aquisição de aprendizagens }\end{array}$} & Discordo Totalmente & 0 & 0,0 & \multirow{4}{*}{3,55} & \multirow{4}{*}{0,506} \\
\hline & Discordo & 0 & 0,0 & & \\
\hline & Concordo & 13 & 28,3 & & \\
\hline & Concordo Totalmente & 16 & $\mathbf{3 4 , 8}$ & & \\
\hline \multirow{4}{*}{$\begin{array}{l}\text { Desenvolvem competências } \\
\text { escolares }\end{array}$} & Discordo Totalmente & 0 & 0,0 & \multirow{4}{*}{3,48} & \multirow{4}{*}{0,509} \\
\hline & Discordo & 0 & 0,0 & & \\
\hline & Concordo & 15 & 32,6 & & \\
\hline & Concordo Totalmente & 14 & 30,4 & & \\
\hline \multirow{4}{*}{$\begin{array}{l}\text { Ajudam os alunos com } \\
\text { Paralisia Cerebral a adquirir } \\
\text { conhecimentos novos e a } \\
\text { consolidá-los }\end{array}$} & Discordo Totalmente & 0 & 0,0 & \multirow{4}{*}{3,45} & \multirow{4}{*}{0,506} \\
\hline & Discordo & 0 & 0,0 & & \\
\hline & Concordo & 16 & 34,8 & & \\
\hline & Concordo Totalmente & 13 & 28,3 & & \\
\hline \multirow{2}{*}{ Outra } & $\begin{array}{l}\text { Trabalho de pares entre } \\
\text { profissionais }\end{array}$ & 1 & 2,2 & \multirow[b]{2}{*}{-} & \multirow[b]{2}{*}{-} \\
\hline & $\begin{array}{l}\text { Promover a sua } \\
\text { autoestima }\end{array}$ & 1 & 2,2 & & \\
\hline
\end{tabular}

Quanto ao contributo das TIC para a promoção da comunicação e da aprendizagem em alunos com PC, e verificámos que a utilização das TIC, nomeadamente, do computador com software adequado aos alunos observados, ajudou tanto a terapeuta da fala como a professora de educação especial a transmitir os conteúdos, como também ajudou os alunos a demonstrar o que sabiam e a comunicar. Além disso, 64,3\% dos inquiridos referiu recorrer a tecnologias de apoio para colmatar as dificuldades apresentadas pelos alunos com PC (cf. Tabela 7).

\section{Tabela 7}

Estratégias utilizadas em alunos com Paralisia Cerebral para os ajudar a colmatar as dificuldades

\begin{tabular}{lccc}
\hline \multicolumn{1}{c}{ Estratégias } & $\mathrm{n}$ & $\%$ & \% válida \\
\hline Recurso a tecnologias de apoio & 9 & 19,6 & $\mathbf{6 4 , 3}$ \\
\hline $\begin{array}{l}\text { Sensibilização da comunidade escolar; formação; } \\
\text { trabalho educativo }\end{array}$ & 2 & 4,3 & 14,3 \\
\hline Tutoria; ensino individualizado; trabalho de pares & 3 & 6,5 & 21,4 \\
\hline Não Respondeu & 32 & 69,6 & 100,0 \\
\hline Total & 46 & 100,0 & \\
\hline
\end{tabular}

\subsection{Discussão dos resultados}

Atendendo aos objetivos traçados para este estudo e de acordo com os resultados obtidos, começa-se por traçar um perfil sociodemográfico e profissional dos 46 professores inquiridos, dos quais a maioria $(91,3 \%)$ é 
do sexo feminino, com uma idade mínima de 33 anos e a máxima de 55 anos. Constatou-se que $41,3 \%$ dos professores tem, como tempo de serviço, período igual ou inferior a cinco anos. $\mathrm{O}$ grupo mais representativo da amostra está inserido no $110(\mathrm{n}=17 ; 37 \%)$, havendo uma prevalência de professores contratados (63\%), com maior representatividade os que lecionam no $1^{\circ}$ ciclo $(34,1 \%)$.

Em relação ao primeiro objetivo, que visava conhecer as estratégias utilizadas em alunos com PC para os ajudar a colmatar as dificuldades, apurou-se que a maioria $(64,3 \%)$ mencionou recorrer a tecnologias de apoio. Em consonância com os dados apurados, sobretudo no que respeita à utilização das tecnologias de apoio, é necessário explorar as possibilidades que o software e o hardware oferecem, como elementos facilitadores de comunicação e de estímulo à aprendizagem de crianças com PC (Reis \& Sampaio, 2009).

As TIC representam um contributo inestimável no campo da habilitação e educação, com especial incidência nas áreas do desenvolvimento cognitivo, psicomotor, como meio aumentativo e/ou alternativo de comunicação e, ainda, como meio facilitador da realização de uma tarefa. Segundo Souza (2009), as TIC devem proporcionar à criança possibilidades de desenvolvimento. Junto dos alunos com PC, as tecnologias de apoio são, por vezes, a única alternativa de interação com o meio, possibilitando-lhes um verdadeiro acesso à educação, à socialização e comunicação, devendo ser introduzidas $\mathrm{o}$ mais precocemente possível (Martins \& Leitão, 2012).

Um sistema de educação inclusivo deve estruturar-se e desenvolver-se no respeito pela diversidade das características das crianças, pelas diferentes necessidades ou problemas e, não obstante, a diferenciação pedagógica. Neste sentido, o Decreto-Lei n. ${ }^{\circ} 3 / 2008$, de 7 de janeiro, veio enquadrar as respostas educativas a desenvolver, no âmbito da adaptação do processo educativo, delimitando os princípios orientadores, dos quais se salienta que as tecnologias de apoio integram os dispositivos facilitadores para melhoria da funcionalidade e redução da incapacidade do aluno.

Em relação ao segundo objetivo, que pretendia conhecer as atividades a que os alunos com PC respondem melhor, a maioria dos professores inquiridos $(77,3 \%)$ mencionou que estes alunos o fazem mais com mais frequência quando são apoiados de forma individual. Estes resultados sugerem que o trabalho com alunos com PC deve ser também individualizado e com recurso a metodologias de ensino ajustadas às necessidades de cada aluno, de modo a que estes possam desenvolver a sua capacidade comunicativa e se sintam mais motivados para o processo de ensino e aprendizagem. 
No que concerne às atividades a que os alunos com PC aderem melhor, verificou-se que $30,4 \%$ dos sujeitos inquiridos indicaram as atividades de papel e lápis, 26,1\% referiram atividades multimédia, 23,9\% indicaram as atividades de expressão plástica, 21,7\% mencionaram as atividades físicas e 19,6\% indicaram as atividades musicais. Esta variedade de atividades, às quais os alunos com PC aderem com mais motivação, é denotativa da necessidade de práticas pedagógicas também elas diversificadas para que se possa contribuir para a plena inclusão escolar destes alunos e para que os mesmos possam ter ganhos a nível da autonomia, da capacidade de socialização, do desenvolvimento psicomotor, do autoconceito e da autoestima. Nesta linha de pensamento, menciona-se Lagarto (2007), quando diz que ensinar alunos com NEE, de forma eficaz, exige recursos e estratégias diversificados para que se possa criar contextos de ensino e aprendizagem o mais equitativas possível. Se assim não acontecer, a construção de aprendizagens e a inclusão educativa e social destas crianças ficam seriamente comprometidas.

Relativamente à utilização das TIC nas práticas pedagógicas com alunos com PC, sendo este o terceiro objetivo, apurou-se que a maioria dos professores inquiridos $(57,9 \%)$ recorre às mesmas com muita frequência. A este propósito importa referir que o aluno com PC, ao aceder a este tipo de recurso, tem a possibilidade da comunicação alternativa, podendo levar a uma interação mais satisfatória no contexto em que se insere, favorecendo expressões significativas de pensamento, que por comprometimentos motores, a sua linguagem oral (fala) e linguagem gráfica (escrita) encontram-se prejudicadas, mas a sua linguagem interna, isto é, os seus pensamentos, ideias, sentimentos e desejos, encontram-se em processo de construção, sendo as TIC um recurso para a sua estimulação (Sancho, 2006). Porém, salienta-se que o papel das TIC só poderá ser eficaz para os alunos com PC se a sua integração condicionar outros polos do sistema, como, por exemplo, uma renovação pedagógica assente em programas educativos que integrem as tecnologias, uma formação para a autoaprendizagem contínua e, ainda, a redefinição dos papéis dos protagonistas: professor e alunos (Fonseca \& Lima, 2009).

Numa sociedade inclusiva de informação, as abordagens educativas e tecnológicas apropriadas têm que estar adaptadas às exigências de todos os utilizadores, incluindo os alunos que apresentam NEE, no caso concreto os alunos com PC. Assim, o acesso às TIC pode reduzir as desigualdades na educação, podendo ser uma ferramenta poderosa no apoio à inclusão educativa (Ramos et al., 2001). Aliás, a literatura indica que o recurso às TIC pode contribuir para uma maior eficácia do processo 
de ensino e aprendizagem, em particular de alunos com NEE e/ou em alunos menos competentes que os seus pares (Cook, 1995; Flores, Peres, \& Escola, 2009; Papert, 1997; Pastor, 1994; Ponte, 1996; Rodrigues, 1988).

Em relação à utilização do computador nas aulas, verificou-se que este é um instrumento com funcionalidade para os inquiridos, tendo a maioria dos professores $(70,6 \%)$ referido a frequente utilização do computador em contexto de sala de aula. É precisamente sobre a funcionalidade do computador para apoiar os alunos com NEE, que Reis e Sampaio (2009) afirmam que o uso destas ajudas tecnológicas pode ser visto como um grande salto na qualidade de vida dos alunos com PC, pois, através das diversas adaptações possíveis, por exemplo, num computador, este pode tornar-se num importante agente facilitador da aprendizagem, instrumento imprescindível na possibilidade de comunicação, assumindo, deste modo, o papel de fundamental promotor da inclusão escolar e social destes alunos.

Importa ressalvar que, em função das dificuldades apresentadas pelos alunos com PC, os resultados desta intervenção com as TIC (computador) não serão visíveis a curto prazo. Este é um parecer expresso por Reis e Sampaio (2009), que salientam a importância de se ressaltar que o trabalho com as TIC adaptadas a alunos com PC desenvolve-se num ritmo muito lento e que é frequente ter de se retomar o trabalho com objetos concretos, mas a certeza de resultados positivos torna-o muito gratificante e apresenta uma infinidade de possibilidades.

Outro resultado a que se chegou prende-se com o facto de $39,1 \%$ dos docentes inquiridos concordarem com o pressuposto de que a utilização das TIC contribui para a aquisição de aprendizagens, ajuda os alunos a ultrapassar/minimizar algumas das dificuldades $(32,6 \%)$, bem como potencia o desenvolvimento da comunicação $(32,6 \%)$. Verificámos igualmente que $34,8 \%$ dos docentes consideram que as TIC facilitam o processo de inclusão dos alunos com PC, tendo as mesmas potencialidades para inovar e melhorar o seu processo educativo $(32,6 \%)$, melhorar a sua qualidade de vida, ajudando-os a desenvolver competências escolares $(34,8 \%)$ e na aquisição de conhecimentos novos e sua consolidação $(32,6 \%)$. Atendendo a estes resultados, não se pode negligenciar as possibilidades das TIC no processo de ensino e aprendizagem dos alunos com PC. Isto porque, as TIC têm uma grande importância no processo de inclusão educativa destes alunos, o que implica uma adaptação das mesmas e um trabalho desenvolvido num ambiente estimulador para facilitar a sua aprendizagem e as suas possíveis interações sociais (Souza, 2009).

Uma outra perspetiva, defendida por vários autores (Fonseca \& Lima, 2009; Reis \& Sampaio, 2009), está relacionada com a experiência 
contínua proporcionada às crianças na interação com as TIC, que resulta em vivências prazerosas, uma vez que se apercebem do seu sucesso face a situações desafiadoras, com ganhos a nível do autoconceito e da autoestima.

Em suma, concluímos que, para determinadas pessoas, expressar as suas necessidades, desejos, afetos, sentimentos, opções, conhecimentos, opiniões e, deste modo, interagir e atuar com os outros, é um ato difícil de realizar. É o caso de alguns alunos com PC que, devido à dificuldade e/ou impossibilidade de exercerem um controlo correto sobre o seu aparelho fonador, estão limitados ou impedidos de se exprimirem oralmente. No entanto, alguns alunos com PC possuem capacidades e necessidades comunicativas idênticas às dos seus pares sem PC que, normalmente, comunicam através da fala. Assim, poderá estar apenas afetada a fala, mas não estar afetada a compreensão e os conceitos linguísticos. Para estes alunos, é fundamental proporcionar-lhes, tão cedo quanto possível, um sistema alternativo ou aumentativo de comunicação, que consiste num conjunto de técnicas, ajudas, estratégias e capacidades que uma pessoa impossibilitada de falar usa para comunicar, sendo constituídos por símbolos e sistemas de símbolos que necessitam de um suporte, como seja uma ajuda técnica ou um dispositivo de suporte, e as TIC são precisamente um meio que pode facultar tais ajudas; são uma ferramenta valiosa na educação das pessoas com deficiência e ajudam a aumentar o seu acesso a infraestruturas (UNESCO, 2005).

Foi também nosso intuito observar a utilização das TIC em dois alunos com PC, procurando verificar a influência desta utilização na concretização de tarefas escolares e consequente promoção da aprendizagem. Assim, após as observações efetuadas, constatámos que os dois alunos manifestaram-se mais motivados, interessados e empenhados em realizar as tarefas escolares no computador, demonstrando alguma autonomia na sua exploração e um feedback imediato e autocorretivo. As suas dificuldades de focalização e de manutenção de atenção resultaram na necessidade de diversificar as atividades. Além disso, o computador assumiu um papel relevante no desenvolvimento das capacidades psicomotoras e comunicativas dos alunos, ajudando-os a comunicar.

Importa ainda identificar as limitações encontradas na concretização deste estudo, salientamos o número reduzido de questionários preenchidos, o facto de a questão sobre a experiência docente com alunos com PC só ter sido considerada para a caracterização da amostra e não como questão de filtro, o que resultou em elevadas percentagens de não respostas em questões direcionadas para a prática pedagógica com estes alunos. 


\section{CONCLUSÕES}

A aprendizagem em conjunto é privilegiada na escola e é no contacto com os outros que a educação acontece e "as potencialidades e as falibilidades das pessoas moldam a extensão e a textura do crescimento de cada um de nós” (O`Brien, 1999, p.65).

Face às limitações funcionais apresentadas pelos alunos com PC, estes podem desenvolver experiências cognitivas, sociais e emocionais de acordo com as ofertas de exploração que lhe são facultadas, no seu processo de ensino e aprendizagem. É neste âmbito que as TIC se apresentam como um meio facilitador dessas experiências. Como refere Alba (2006), a tecnologia tem servido para dominar a natureza, adaptar o mundo às necessidades do Homem ou, inclusive, ampliar as suas capacidades. Mas, as suas potencialidades não se esgotam aqui, na medida em que um dos slogans que acompanha o imperativo avanço tecnológico é o potencial dos softwares e hardwares, que têm contribuído para a melhoria da qualidade de vida de todas as pessoas.

Ao longo desta investigação, verificámos que as TIC têm um papel importante no processo de ensino e aprendizagem dos alunos com PC, pois estes encontram nas mesmas uma ajuda valiosa para a melhoria da sua inclusão escolar e social. Isto vai ao encontro do que foi dito por Radabaugh (1993), para as pessoas sem deficiência, a tecnologia torna as coisas mais fáceis; para as pessoas com deficiência, a tecnologia torna as coisas possíveis. Sancho (2006) tem a mesma opinião, pois, para ele, as tecnologias de apoio proporcionam mais autonomia e qualidade de vida às pessoas e possibilitam-lhes a realização de atividades de aprendizagem de forma mais eficaz. Por isso, hoje em dia, o professor já não é o mero transmissor de informação, mas deverá ser inovador, flexível e investigador de maneira a garantir um ensino com qualidade a todos os alunos, independentemente das suas limitações. De acordo com Cury (2008, p. 22), "educar não é repetir palavras, é criar ideias, é encantar".

Neste sentido, as TIC podem ser a chave para uma educação de sucesso para todos os alunos, independentemente das suas características pessoais, pois podem ser um meio que facilita a integração e reforça a igualdade de todos os alunos, mesmo daqueles que têm NEE e, particularmente, dos que têm PC. Segundo Silva (2004), nem todos têm as mesmas oportunidades de acesso à informação, mesmo estando apenas à distância de um clique na Internet para aceder à "Aldeia global". Isto por vezes deve-se a problemas económicos, de infraestrutura ou de acessibilidade. Por isso, a escola tem a obrigação de dar essa oportunidade aos alunos, incluindo as TIC nas suas práticas letivas. Apesar do uso das TIC por si só não garantir uma melhoria qualitativa nas aprendizagens dos alunos ou nas práticas letivas dos professores, pode ser 
visto como uma ferramenta poderosa no acesso e processamento da informação e comunicação global, já que permite uma flexibilização das estratégias de ensino e aprendizagem, indo ao encontro das necessidades individuais de cada aluno (Rodrigues, 1988). No entanto, não basta estar em contacto com as TIC para adquirir novos conhecimentos ou destrezas. Devem ser utilizadas como uma forma de apoio à aprendizagem (Ponte, 2002).

De acordo com os resultados obtidos no estudo aqui apresentado, a dificuldade mais referenciada nos alunos com PC está relacionada com a comunicação e com a aprendizagem e é aqui que estamos cientes que a utilização das TIC pode ser um passo em frente para o sucesso escolar destes alunos. A maioria dos professores referiu que recorre a tecnologias de apoio com alunos com PC e que considera que as TIC facilitam o processo de inclusão destes alunos. Há, no entanto, professores que referiram nunca utilizar as TIC. Apesar de nem todos os professores as usarem, concluímos que as TIC são um recurso educativo a que os docentes recorrem com frequência e desempenham um papel determinante no processo de ensino e aprendizagem de alunos com PC favorecendo a aprendizagem e a socialização. Para Ribeiro, Moreira e Almeida (2009), o processo de ensino e aprendizagem está cada vez mais dependente da tecnologia, nomeadamente, para alunos com limitações e que se afastam da aprendizagem padrão.

Concluímos também que, com base nas observações efetuadas, os alunos com PC revelam-se muito mais motivados e empenhados em desenvolver atividades que impliquem o recurso ao computador. Estes testemunhos estão em consonância com a literatura consultada, nomeadamente com a DGIDC (2008), que postula o desenvolvimento da capacidade de comunicação destes alunos através das TIC, o que significará, para os mesmos, uma maior compreensão do que acontece à sua volta, maiores possibilidades de expressarem as suas próprias necessidades e o acesso a atividades mais motivadoras. A par de outros recursos, as TIC ocupam, atualmente, na sociedade, um papel importante no desenvolvimento e sustentação da qualidade de vida desses alunos. Aliar a tecnologia à educação especial é garantir o direito de acesso ao conhecimento. As TIC oferecem um grupo de ferramentas com possibilidades de interação entre os alunos com PC e o mundo exterior, nomeadamente o microssistema sala de aula, onde estão incluídos, facultando-lhes outras formas de comunicação. Estas têm possibilidades de ajudar no desenvolvimento psicossocial, cognitivo, emocional e motor dos alunos com PC. Assim, estas ajudas tecnológicas têm uma função principal, que é agir como um instrumento para superar as barreiras 
decorrentes das limitações dos alunos e de um modelo educativo maioritariamente uniforme.

\section{FONTES E BIBLIOGRAFIA}

Alba, C. (2006). Uma educação sem barreira tecnológicas. TIC e educação inclusiva. In J. M. Sancho \& F. Hernández, (Orgs.) (2006). Tecnologias para transformar a educação (pp. 131-152). Porto Alegre: Artmed.

Almeida, L., \& Freire, T. (2003). Metodologias da investigação em psicologia e educação. Braga: Psiquilíbrios.Baptista, J. (2011). Introdução às Ciências da Educação: temas e problemas da educação inclusiva. Lisboa: Universidade Católica Editora.

Basil, C. (1995). Os alunos com paralisia cerebral: desenvolvimento e educação. In C. Coll, J. Palacios, \& A. Marchesi, (Orgs.). Desenvolvimento Psicológico e Educação: necessidades educativas especiais e aprendizagem escolar (pp. 252-271). Porto Alegre: Artes Médicas.

Bell, J. (2008). Como realizar um projeto de Investigação - Trajetos. Lisboa: Gradiva.

Correia, M. (2003). Inclusão e necessidades educativas especiais. Porto: Porto Editora.

Cruz, M. (2009). Paralisia Cerebral e dificuldades de comunicação: uma proposta de actividade com recurso a tecnologia de apoio. Revista Saber \& Educar/Cadernos de Estudo, 14, 1-16.

Cury, A.J. (2008). Pais brilhantes, professores fascinantes. Rio de Janeiro: Sextante.

Damásio, M. (2007). Tecnologia e educação: as tecnologias da informação e da comunicação e o processo educativo. Lisboa: Editorial Vega.

Decreto-Lei n ${ }^{\circ}$ 3/2008 de 7 de janeiro - Diário da República, 1. ${ }^{\text {a }}$ série N. ${ }^{\circ} 4-7$ de janeiro de 2008 .

Direção Geral de Inovação e Desenvolvimento Curricular (DGIDC) (2008). Educação Especial: Manual de apoio à Pratica. Lisboa: Ministério da Educação.

Flores, P., Peres, A., \& Escola, J. (2009). Integração de Tecnologias na Prática Pedagógica: boas práticas. Acedido em 20 de abril de 2012 em

http://api.ning.com/files/ihNawYsW5hU7j7Ki8NH-

NvaSfDBdcUVxu9U2QD1rKYCnUwtIkLI*TmG6W604WDf-Udx-

fCM $8 *$ rSsfUCFTXCEu-dOa0XzNqSN/xcongressodepsicopedagogia.pdf.

Fonseca, L.F., \& Lima, C.L.A. (2009). Paralisia Cerebral. Neurologia. Ortopedia. Reabilitação. Rio de Janeiro: Editora Guanabara, S.A.. 
Fradinho, M. (2009). O contributo do desporto no Sucesso Escolar dos alunos com Deficiência Motora. Dissertação de Mestrado, Universidade Portucalense: Porto.

Lagarto, J.R. (2007). A escola, a sociedade da informação e as TIC. In J. R. Lagarto (Org.), Na rota da sociedade do conhecimento - as TIC na escola (pp. 7-13). Lisboa: Universidade Católica Editora.

Leite, J., \& Prado, G. (2004). Paralisia Cerebral: aspetos fisioterapêuticos e clínicos. Revista Neurociências, 12, 1. Acedido em 10 de novembro de $2011 \mathrm{em} \mathrm{http://www.revistaneurociencias.com.br.}$

Mahl, E. (2012) Algumas considerações sobre os desafios e ações visando a inclusão educacional. Revista Gefyra, São Miguel do Iguaçu, vol.1, 1, 41-48.

Martins, I. C. \& Leitão, L. (2012). O Aluno com Paralisia Cerebral em contexto educativo: Diferenciação de metodologias e de estratégias. Revista Millenium, 42, 59-67.

Martins, I. C. (2013). O papel da experiência motora no desenvolvimento global: o Aluno com Paralisia Cerebral. Revista Millenium, 45, 45-62.

Martins, I.C. \& Oliveira, A. M. (2013). What does the body have to do with it? Motion extrapolation in individuals with cerebral palsy, Revista de Saúde Pública, 48, 151.

Martínez, J. H. G. (2004). Novas tecnologias e o desafio da educação. In Tedesco, J.C. (Org.). Educação e novas tecnologias: esperança ou incertezas (pp. 95-119). São Paulo: Cortez; Buenos Ayres: Instituto Internacional de Planeamiento de la Educación; Brasília: UNESCO.

Montoya, R.S. (2000). Integración holística de la tecnologia adaptativa. Cádiz: Universidad de Cádiz,

Morato, P. P. (1998). Deficiência mental e aprendizagem. Lisboa: Secretariado Nacional para a Reabilitação e Integração das Pessoas com Deficiência.

Moura, M. (2006). As Tecnologias de informação e comunicação no apoio a alunos do ensino básico com paralisia cerebral: estudo múltiplo de casos. Dissertação de Mestrado. Braga: Universidade do Minho.

O’Brien, J. \& O'Brien C. (1999) A Inclusão como uma Força para a Renovação da Escola. In Stainback, S. \& Stainback, W. (Org.). Inclusão- Um Guia para Educadores (pp.65-72). Porto Alegre: Artes Médicas.

Papert, S. (1997). A Família em Rede. Lisboa: Relógio d' Água.

Pastor, C. A. (1994). Utilización didáctica de recursos tecnológicos como respuesta a la diversidad. In J. M. Sancho (Ed.), Para una tecnología educativa (pp. 221-241). Barcelona: Horsori. 
Ponte, J. P. (2002). As TIC no início da escolaridade - Perspectivas para a formação inicial de professores. In J. P. Ponte (Org.). A Formação para a Integração da TIC na Educação Pré-Escolar e no $1^{\circ}$ Ciclo do Ensino Básico (pp. 19-26). Porto: Porto Editora.

Ponte, J.P. (1996). O computador pode ser também um instrumento da educação. Lisboa: Texto Editores.

Radabaugh, M.P. (1993). Study on the Financing of Assistive Technology Devices of Services for Individuals with Disabilities - A report to the president and the congress of the United State, National Council on Disability. Acedido em 16 de abril de 2012 em http://www.ccclivecaption.com Acesso em 04 dez. 2007.

Reis, N.M.M., \& Sampaio, M.J.T. (2009). Utilização da Informática na Paralisia Cerebral: possibilidades e recursos na clínica da terapia ocupacional. In L. C. L. Andrade \& L. F. Fonseca (Org.). Paralisia Cerebral. Neurologia. Ortopedia. Reabilitação (pp. 289-298). Rio de Janeiro: Editora Guanabara, S.A.

Ribeiro, J. (2011). Do Papel para o digital: A Adaptação de contextos educativos digitais de Alunos com NEE. Tecnologias da Informação em Educação, n. ${ }^{\circ}$ especial (pp 9-32).

Ribeiro, J., Moreira, A., \& Almeida, A. (2009). An approach to Inclusion through Information and Communication Technology. Actas do I Congresso Internacional Família, Escola e Sociedade - Educação Especial, Educare, Porto 9 a 11 de Julho de 2009, 1089-1102.

Rodrigues, D. (1988). Palavras de abertura. Actas do seminário. Lisboa: Polo do Projecto Minerva da UTL - ISEF/EER.

Rosenbaum, P., Paneth, N., Levinton, A., Goldstein, M., \& Bax, M.C. (2007). A report: the definition and classification of cerebral palsy. Developmental Medicine and Child Neurology, 11, 295-297.

Sancho, J.M. (2006). Tecnologias para Transformar a Educação. Porto Alegre: Artmed.

Silva, A. (2004). Ensinar e aprender com as Tecnologias: Um estudo sobre as atitudes, formação, condições de equipamento e utilização nas escolas do $1^{\circ}$ Ciclo do Ensino Básico do Concelho de Cabeceiras de Basto. Dissertação de Mestrado, Universidade do Minho, Braga.

Silva, F. (2003). Tecnologias e formação inicial de professores: um estudo de opiniões e práticas (Manuscrito não publicado). Lisboa: Faculdade de Psicologia e de Ciências da Educação da Universidade de Lisboa.

Souza, P.A. (2009). Esporteterapia como Indutora da Neuroplasticidade na Paralisia Cerebral. In C. L. A. Lima, \& L.F. Fonseca (Orgs.), Paralisia Cerebral. Neurologia. Ortopedia. Reabilitação (pp. 421432). Rio de Janeiro: Editora Guanabara, S.A. 
UNESCO (2005). Orientações para a inclusão - Garantindo o Acesso à Educação para Todos. Editado em França, UNESCO.

UNESCO (2011). ICTs in Education for people with disabilities. Review of innovative practice. Editado em Moscow, UNESCO.

Williams, P. (2005). Using information and communication technology with special educational needs students Acedido em 16 de abril de 2012 em http://www.emeraldinsight.com/journals.htm?issn=0001$253 X \&$ volume $=57 \&$ issue $=6$ 